\title{
Active Learning Strategies: An Illustrative Approach to Bring out Better Learning Outcomes from Science, Technology, Engineering and Mathematics (STEM) Students
}

\author{
http://dx.doi.org/10.3991/ijet.v9i9.3979
}

A.Srinath

K L University, Green Fields, Vaddeswaram, Guntur Dist, India.

\begin{abstract}
Teaching in a Teacher centric manner has been the mainframe teaching style in engineering education, however students feel it as a single sided approach and feel they are only passive listeners thus this style has now paved way to a Learner centric style of teaching-learning which is ACTIVE LEARNING, wherein every student is actively involved in one or the other form of learning and thus gets a chance to develop the key aspects of the course either on their own or by being a member of an active-learning group. They thus not only learn and practice the course contents but also learn managerial and team skills which are of much importance in present scenario in regard to Industries and companies where these students will be ultimately hired as employees. Professional education is making one's students ready for the profession which includes team work, management and technical skills, thus Active learning has emerged as a mainframe tool for cherishing this aim of professional education, especially Science, Technology, Engineering and Management (STEM) education. This paper aims to focus on a few facets of this active learning process and give an overview to the teaching faculty as well as students on what their individual roles must be like in this process for getting the most out of this process.
\end{abstract}

\section{PRACTICAL EXAMPLES}

Using practical examples in the classroom can link theoretical concepts and the thus derived ideas to real world situations and help engage students from many perspectives. Teaching methods such as effective usage of case studies and incorporating brainstorming sessions in lecture classes are found to be of great benefit.

\section{A. Connecting theory with real-time applications}

Students generally express their concern regarding the need for more industry driven and practical examples to reinforce theory in the classroom. The use of practical examples can help one to connect theory with practical applications more effectively the teaching to learning. The introduction of practical examples does not imply; elimination of theory, but rather the extension of theory taught in the classroom. It is important to alongside develop theoretical and practical base for knowledge, since both complement each other and none is useful without the other. The use of practical examples in the classroom is oriented to achieve the following objectives:

1. To illustrate, explain new and novel approaches in a course, making the theoretical base of the material more accessible to the students. Practical examples helps the students understand new concepts being thus introduced.

2. Teach students the methods in applying their knowledge of a course to new situations that are not directly covered in lecture class. The aim here is to demonstrate to the students that not only what they are learning has practical applications but, more importantly, how the concept can be applied by their levels of understanding of the basic principles to such real world problems.

Practical examples can and must be included at all levels of the course irrespective of whether it is an entry level one or at higher level. When zeroing in on examples to be used for instruction, it is important that one makes the examples as clear and straightforward as possible. The key is to make the examples as simple as possible, and to make sure that they aptly demonstrate the desired theoretical principle. Whenever possible, the examples should be designed such that the students' physical senses are brought out. Examples that the students are likely to enjoy include those that require them to use their sense organs of sight, feeling, hearing or smell. The following guidelines are essential, when one is in the process of implementing practical examples:

Firstly one (teacher) has to understand the example given and be able to explain it. If one cannot provide a clear explanation for the example, the example will rather confuse the students than what it will help them.

Before giving a demonstration or a home assignment, it is essential that one carries out the assignment by themselves. This will ensure that one exactly knows what the students will see. It will also help one to anticipate questions. Giving an assignment or demonstration that doesn't work is frustrating to the students and is bad for one's credibility.

Choosing examples that are relevant to the student is a key aspect. Examples that students can observe in their day to day life as opposed to those in a film, online or on television are better. One must try to find examples that the students can observe on campus or at home. Pulling out examples from recent events like, for instance, explaining the cause of a design failure of a fly over bridge that collapsed recently and was in the news. It is essential to explain the basic principles behind a new or commonly used product, like the process design of a disk drive in a 
computer can be easily linked to Bernoulli's equations in a Fluid Mechanics course.

Using examples that are not familiar to students is another essential feature. Often, such examples will ignite their interest more rapidly because of their novelty. If one chooses a well-known case, they must be careful; in regard to the pre-existing assumptions about the material in the students', which may or may not be a grounded fact.

\section{B. Types of Practical Examples}

Practical examples can be grouped into the following broad categories:

1. Those that can assist in the explanation of theory and new concepts,

2. Those that illustrate the application of basic principles,

3. Those that can both explain theory and new concepts and illustrate their application.

Practical examples can also be broken down into various types based on the format in which they are applied.

\section{Process of Explaining the Practical Examples}

\section{1) Analogy}

The analogy is very helpful tool for explaining newer concepts. Here, the instructor links the new concept to an idea which the students can easily picture out in their minds. An example of an analogy would be to explain the concept of the conservation of energy in terms of money in a bank account, wherein the student can be made to imagine the money in a current account as being analogous to kinetic energy, similarly, money in the savings accounts can be made to be imagined as being analogous to potential energy, respectively. Just as money can be transferred between these different accounts, so can energy be transferred between the different forms. The concept of frictional energy losses can thus be easily related to the debiting of money from the accounts (say, for paying the rent of a house / paying electricity bills).

\section{2) Sensing}

Sensing examples are designed such that students can feel the science behind the phenomena. The objective is to have the students carry out experiments that allow them to sense different parameters that enter into the theory. An example of this would be to study the relationship between speed and torque for a gear system using a variablespeed bicycle. The students' assignment would be to flip a variable-speed bicycle upside down, switch through all the gear combinations while pedalling it by hand, and physically sense how the speed and torque for a particular gear setting are related. Clearly, the emphasis in this technique is not to teach or explain a new concept but to give a known concept its much needed meaning by having the students sense it.

\section{3) Secondary Effects}

Secondary effects demonstrate the fact that many a times the explanation of an engineering phenomenon cannot. The purpose here is to get the students really consider all the possible explanations besides the most obvious one. A classic example of this would be an observation of the direction of movement of a helium balloon tied to the floor of a moving vehicle when the vehicle accelerates. Typically one would expect the balloon to move backwards when the vehicle accelerates, due to the inertia of the balloon. However this would be the case if a steel ball were to be suspended from the ceiling of the vehicle. In fact, the students will notice that the balloon moves forward as the vehicle accelerates. An investigation of the forces acting on the balloon can be done either as homework or as a class discussion. By doing so, the students should eventually come to realize that the balloon is pushed forward by the buoyancy force acting on it. As the vehicle accelerates, the air in the back of it is compressed slightly, resulting in a density gradient from the front to the rear of the vehicle. The helium in the balloon is lighter than air and therefore experiences a buoyancy force in the horizontal direction.

\section{4) Observations}

Observations that the student can make outside of class can help demonstrate basic principles currently being studied in the class. The example can be carried out as a take home assignment where the students are required to go and observe a phenomenon that they can readily see, feel, hear and/or smell, and to summarize their observations later. The students bring back their observations to class and the instructor leads a discussion of what the students observed and what those observations mean. This type of exercise not only helps with the understanding of a new concept or basic principle, but also teaches the students how to observe a phenomenon before trying to analyse it.

\section{5) Demonstrations \{Experimental or Mathematical\}}

The demonstration examples can be done either as an experimental exercise carried out in class with small models, or as a mathematical exercise carried out on the board or computer through a Projector to explain a physical phenomenon. This can be particularly instructive when the students are aware of the phenomena but are not able to explain the science behind it.

\section{6) Experimental}

An experimental demonstration requires physical equipment. While finding the right equipment is not always possible, some examples require materials as simple as a paper clip or piece of paper. For instance, the factors affecting the aerodynamic drag and lift forces can be demonstrated with a simple piece of writing paper. One can hold a flat sheet of paper parallel to the floor and drop it, while observing its rate of descent. Then taking the same sheet of paper and crumpling it and then drop it to observe its rate of descent. In both cases we have the same material, the same mass, and the same gravitational force acting on the system. Therefore, these parameters can be eliminated from consideration. By further eliminating other parameters, the students can be led to understand that the important parameter is the aerodynamic drag acting on the two different objects. Similarly, important governing parameters in other systems could be deduced. For instance, tests could be run with the same object shapes but with different projected areas. By observing how the time of fall depends on the various parameters, the students could arrive at the main governing parameters.

\section{7) Mathematical}

The purpose of a mathematical demonstration is to explain, the theory developed in a class, the science behind some phenomena that the students have seen or heard of. This can be particularly enlightening if the phenomenon is 
such that everyone knows about it, but very few realize what really is happening. For instance, the term float valve in an internal combustion engine can be explained by modelling the valve as a train of solid links and springs, and then writing the equations of motion for the valve.

\section{SHOW AND TELL}

"If one can explain a concept to someone else, then one truly understands the concept."

\section{A. Reversing Student Roles}

The Show and Tell technique is another form of the using Practical Examples to make students learn. However, in this technique the role of the student is reversed to that of a teacher, thereby changing the student's perspective of the problem. The basic objective of the Show and Telll technique is that if one can explain a concept to someone else, then one truly understands the concept.

\section{B. Scope}

A typical Show and Tell project requires a student or a group of students to explain a theory or phenomenon to the rest of the class and to demonstrate a physical example that helps visualize the phenomenon. Almost any example that one can convincingly demonstrate in a classroom would be appropriate for a Show and Tell project. However, it should be noted that, as with the case of the Practical Examples technique, the concept to be explained by the students should be relatively simple and straightforward. The purpose of this exercise is to challenge the students to Expanding Teaching Strategies, come up with a creative solution to the problem at hand without overwhelming them.

To avoid embarrassing situations and to ensure that the demonstrations are useful to the entire class, it is also important for the instructor to know beforehand what the students plan to present.

\section{CASE STUdies}

"A case study is an account of an actual activity / event/ problem, containing some of the background and complexities actually encountered by a practicing person in real world."

\section{A. Bringing "Real-World" Scenarios into the Classroom}

A case study is an account of an actual activity /event / problem containing some of the background and complexities actually encountered by a practicing person in the real world. Since cases are accounts of real-life activity, they help the students in correlating better the theory to real world. Case studies often involve concepts from other disciplines than one's domain like marketing and management, concepts that an engineering professional need to know anyway are used in engineering courses. In addition, the case method promotes discussions in class and can be thought of as a way of obtaining feedback from the students.

\section{B. Scope}

Engineering case studies can be included at all levels of the engineering curriculum. The hardest part of using case studies is finding cases that best fit with a particular class's topic. This, however, must not deter one from using the case study method, as there are many texts available on case studies. Faculty can use contacts in an industry are other great resources for finding cases. With a little work, it should not be too hard to find a good case for any class.

\section{Strategies}

\section{1) Comprehensions:}

Students are usually given written material regarding a case, and are asked to read it and answer a series of questions pertaining to various aspects of the case. The students can be made to work either individually or in groups. The following are some tips to remember when using a case study:

- The case study questions may increase the amount of work the students have to do outside of class. Care must be taken to balance this extra workload with other assignments.

- When using case studies derived from the literature / books, do not stick to using the questions given with the case in the literature / book. Generate new questions that fit topics covered in the class directly.

- While the questions that are assigned form basis of the discussion, be prepared with other questions to guide discussions.

- The goal of the class's use of case should be kept in mind at all times. Keep the discussion from drifting away from this goal.

- Above all, be thoroughly prepared for the discussion. Poor preparation will lead to frustration among the students.

\section{2) Example: Design Change for a Foot-over bridge}

The following case study can be used in a Civil Engineering- Structural Design course. The case helps students discuss how changes in a design during manufacturing and construction can affect the safety of the overall design. The students must consider the following problem:

The on-site engineers want to know if they can change the part of a design to ease construction. As Lead engineer, would one allow the change? Explain why or why not?

The case material must describe the failure of the foot over bridge for example in a star Hotel. The collapse may occur due to a shear failure of the beam when a large group gathers over it to watch a Carnival / Procession on the road below.

The faculty handling the course, must not disclose the effects of the design modification while handing out the case materials; and the students must be simply asked whether or not they would allow the change, and to include any calculations to support their claims.

One fill find roughly, about a quarter of the class will decide that they would allow the change, while the rest may decide that they would not. However, the students who would not allow the change are most likely to produce a variety of answers, not all of which will be close to the right answer. These students who produce the right answers must be asked to describe the failure mechanism to the rest of the class. The faculty must grade the students' work more on the amount of thought put into the case rather than on getting close to the correct answer. The whole exercise will take only one full class period in addition to the time required for grading. 


\section{TEAChing With CASE StUdies}

\section{A. Managing a Case Study based Assignment}

- Design discussions for small groups: three to six students are an ideal group for setting up a discussion on a case.

- Design the narrative or situation so that it requires participants to reach a judgment, decision, recommendation, prediction or other concrete outcome. If possible, require each group to reach a consensus on the decision.

- Structure the discussion. Provide a series of written questions to guide small group discussion. Pay careful attention to the sequencing of the questions. Early questions might ask participants to make observations about the facts of the case. Later questions could ask for comparisons, contrasts, and analyses of competing observations or hypotheses. Final questions might ask students to take a stand on the matter. The purpose of these questions is to stimulate or guide (but not dictate) participants' observations and analyses. The questions should be impossible to answer with a simple yes or no.

- Debrief to compare group responses. Help the whole class to interpret and understand the implications of their solutions.

- Allow groups to work without instructor interference. Be comfortable with ambiguity and with adopting the non-traditional roles of witness and resource, rather than authority.

\section{B. Designing Case Study Questions for assignments / exams:}

Cases can be more or less directed by the kinds of questions asked, these kinds of questions can be appended to any case, or can be a hand out for participants unfamiliar with case studies. Following are a few sample questions:

- What is the situation? what do one actually know about it from reading the case? (Distinguish between fact and assumptions, which is critical for understanding this case)

- What issues are at stake?

- What questions do one have? What information do one still need? Where and how could one find it?

- What problem(s) need to be solved? (Opportunity to discuss communication versus conflict, gaps between assumptions, and sides of the argument)

- What are all the possible options? What are the pros and cons of each option?

- What are the underlying assumptions for [person $\mathrm{X}$ ] in the case, and where do one see them?

- What criteria should one had used when choosing an option? What does that mean about oner assumptions?

\section{Guided Design Projects}

\section{A. Introducing Practical Design Experience in Classrooms}

Guided design projects aim to bring practical design experience into the classroom. Such projects are often conducted over a period of a semester; the projects give students an opportunity to work in a team environment, apply theory learned in the classroom, and learn about industrial design methodologies.

\section{B. Scope}

Guided design projects are appropriate for any level, but are often reserved for the Third \& Fourth years in Undergraduate engineering courses or they can be used at all years for post-graduate engineering courses. As with the case method, choosing a project is typically the hardest part. Using guided design projects usually requires a lot of preparation by the faculty. One of the best ways to have students appreciate the industrial design methodology is to have them redesign existing systems or products.

\section{Strategies}

The following are some tips to remember when using a guided design project:

- Realize that the product is not as important as the thought processes that go into determining a design. It is not important that the students determine an optimal design. What is important, however, is that they experience the design process.

- Starting before the semester begins, determine the scope of the projects and the goals for the class. It is important that the scope of the project is reasonable; care must be taken to ensure that the students are not overloaded.

- When possible, divide the design into sections. This spreads the work and the grading duties over the semester. Design teams of two or three students are frequently used. This allows for in-depth projects, reduces the grading load of the instructors, and promotes interaction among the students.

\section{Group Work}

\section{1) General Information about Using Groups}

An important aspect of student learning is group work. Making students work together in groups is beneficial and can be used in a variety of contexts. Groups might be created in class or out of class, around projects or weekly homework assignments. Because group composition can have a significant impact on group functioning, one should use a variety of methods to create groups. Allowing students to create their own groups should be done sparingly, as it can consciously or unconsciously be used to create or reinforce social group differences within the class.

Communicate to students the importance of learning to work together. Collaboration, rather than individual effort, is the norm in many STEM fields. Bring in guest speakers from academia, government or industry to discuss the importance of teamwork with one's students, if needed.

2) Reasons for using cooperative groups:

- To facilitate student learning

- To improve interpersonal relationships among students

- To foster students" responsibility for their own learning and the learning of others

- To prepare students to work in groups in their future careers 
E. Types of groups:

- Lab groups

- Homework groups

- Problem solving groups

- Study groups

\section{F. Methods of assigning groups:}

First, consider one's learning objectives. Then, choose a method from the list below that is most appropriate to one's course learning objectives. If one do not have welldefined objectives for group work, one may want to rethink one's use of groups.

- Make heterogeneous groups across certain characteristics such as gender, race, area of residence, and/or level of achievement in a particular discipline, to improve interpersonal relationships among students.

- Ask students to draw a piece of paper with a group number from a bag.

- Allow students to form their own groups. But ultimately, re-align any social, economic or gender biased groups formulated by students, so that such factors are eliminated.

In addition to being aware of group formation issues, pay attention to the length of time students remain in the same group, particularly if the group is not working together well. It is essential that one addresses process issues when students work in groups, and some class time should be allocated in the planning of the course to discuss group process issues throughout the semester. One should help students determine a way to provide feedback to one another about group process and dynamics and a way to keep one aware of within-group functioning. Feedback is particularly important for identifying social identity characteristics that might be a source of problems in groups and for figuring out how to address problems satisfactorily.

\section{G. Create Roles}

When groups are used, make sure that the same individuals do not always put themselves in the position of leadership. Assigning students to roles (e.g., recorder/note taker, reporter, or moderator), or asking students to rotate roles, should reduce the occurrence of this problem.

\section{H. Challenge Assumptions}

Be ready to challenge assumptions that groups will either be aided or hindered by having certain kinds of students in their group. One way to reduce the likelihood of such assumptions manifesting themselves in group work would be to inform the class that each individual brings a different combination of strengths and weaknesses into the group work context and that students should not make assumptions about what these might be. Group exercises that identify the specific resources that each group member contributes can be useful in the early stages of group formation. It is also important to inform students of one's availability to discuss group process problems that the groups themselves are unable to address successfully.

\section{Prevent Isolation of Group Members}

To monitor group interaction, break a large project into smaller units and work with the groups to achieve their goals step-by-step. Dividing the project can make it easier to observe student-student interactions. This technique is known as "Scaffolding". One may need to make an extra effort to reduce the chances that a student who is different from the majority of the class will feel isolated For example, if students are shunning a classmate during smallgroup activities because of some reason, one have a responsibility to intervene on behalf of the excluded student.

Even when guidelines have been established for participation and responsibilities within groups, problems may arise. It is essential to act quickly when they do. One could begin by reviewing the guidelines for group work. An initial change (if students are forming their own groups) would be to assign individuals to groups and make sure each individual within the group has a role. Another option would be to put students in pairs. It is more difficult to exclude an individual when there are only two participants. If all else fails, it would be important to set up a meeting with the excluded student. Together, one could generate a variety of actions that could be taken to improve the classroom climate. This meeting would be a show of support for the student. While it is important to solicit student input, one cannot expect the student to have the time or experience to solve the problem. If efforts are made to improve the situation and little change occurs, one might speak to one's coinstructors or to an administrator.

\section{REFERENCES}

[1] University of North Carolina at Chapel Hill Center for Teaching and Learning, Teaching for Inclusion: Your Diversity and the College Classroom, , September 2007.

[2] R. M. Felder and L. K. Silverman, Teaching and Learning Styles in Engineering Education, 1988, Engineering Education, 78 (7), p. 680.

[3] National Academy of Sciences, Science Teaching Reconsidered: A Handbook (1997), National Academies Press, Washington, DC.

[4] John Wiley \& Sons, Inc., from - Tools for Teaching by B. G. Davis, Copyright ( 1993, John Wiley \& Sons).

[5] National Institute for Science Education , Field-Tested Learning Assessment Guide for science, math, engineering and technology instructors.

[6] Sherrill L. Sellers, Jean Roberts, Levi Giovanetto Katherine Friedrich, Caroline Hammargren, Reaching all students, Second Edition, 2007

\section{AUTHOR}

A.Srinath is with Koneru Lakshmaiah Education Foundation (K L University), Green Fields, Vaddeswaram, Guntur Dist, A.P. 522 502, India.

Submitted 22 June 2014. Published as resubmitted by the author 15 October 2014. 